\title{
A Study on Barriers to Implement E-Waste Management
}

\author{
Paul Wong Shan Yuan ${ }^{1}, \mathrm{Ng}$ Kit Mun ${ }^{1}$, and Salini Devi Rajendran ${ }^{{ }^{*}}$ \\ ${ }^{1}$ Faculty of Business and Information Science, UCSI University, Jalan Menara Gading, 56000 Cheras, Kuala Lumpur, Malaysia.
}

\begin{abstract}
The increasing of electronic waste (E-waste) is not a new issue in the world and it has been causing trouble throughout the world. This study is conducted to determine and analyze various factors that affect the barriers of E-waste management among the household in Cheras, Malaysia. This study has identified the four independent variables that will affect the implementation of e-waste management among household in Cheras namely lack of awareness, lack of knowledge, lack of cooperation and lack of facilities. Normality test, reliability test and multiple regression analysis with ANOVA test are used to analyse the data in this study. The result shows that all mentions independent variables have a positive relationship with the barriers of implementing e-waste management among households in Cheras. Among these four variables, lack of facilities has the strongest relationship toward the barriers of implementing e-waste management among household in Cheras as it has the lowest significant value which was 0.000 . The study recommends of legalize the policies, rules and regulations in order for household to increase their practice on e-waste management and also implement the teaching of e-waste management to increase the knowledge to the young generations.
\end{abstract}

\section{INTRODUCTION}

With the evolution of economy lead the high consumption of EEE and it has become a central issue all over the world. The usage of electrical and electronic equipment is becoming more popular in today's world [1]. With the increasing usage of electronic and electrical equipment (EEE), electronic waste (E-waste) is growing rapidly and become a common global issue to all of the developing nations, the waste of the electrical and electronic equipment is mushrooming all over the world. E-waste is the fastest growing waste compared to others general waste. The rate of e-waste is three times faster than general waste [2]. When the electrical and electronic products' life span completed, it becomes electronic waste. E-waste has become a major issue for developed countries as well as developing countries. The consumption of EEE is rising and which has brought a huge impact to the environment and human health.

According to Bodamer (2015), United States of America (USA) has generated 7.795 million of e-wastes in the year of 2014 followed by China has generated 6.65 million and Japan has generated 2.43 million of e-waste [3]. These three countries have contributed most of the ewastes compared to other countries. China has produces a lot of e-waste annually which contributed by washing machines, TV sets, computers and mobile phones. In Beijing, China is one of the biggest consumer markets of electrical products and has generated 158.3 thousand tons of e-waste in 2010. It has generated e-waste with the average growth of $5.2 \%$ in the following few years [4]. Most of the e-waste is generated by households, offices, private institutions and the government [5]. The main sources that generated electronic waste in China are because of the domestic generation and imports of electrical products [4]. E-waste recycling in Beijing is not well practiced by the residents. The e-waste is not being reused and recycled due to lack of reclamation channels [4]. Many people do not know how to deal with the unusable electrical products, so they just kept the ewaste in their homes as well as in offices. Most of the household will store the e-waste for several months to years due to they do not know how to deal with the endof-life (EOL) of the electronic products. The residents who keep the e-waste will cause them unable to recycle by recycling system which action will generate more ewaste. The e-waste also flows into the second-hand market after they are being collected and repaired.

Meanwhile, Malaysia is having the same issues as in other countries. The average of 700 kilotons of e-waste generated by household per year and most of them are contributed by television and mobile phone [1]. Malaysia has produced 415 kilotons of electrical and electronic equipment (EEE) in 2012, and which has generated 289.32 kilotons of e-waste [6]. The practice of recycling in Malaysia is still at the initial stage and the participation of residents in recycling practice is very low. The recycling rate in Malaysia is very low compared to others developed countries [7]. There is a record in 2012; the recycling rate was only $9 \%$ for that particular year. It is much lower than our neighboring countries. The average of recycling rate in Malaysia is only 5\% [7].

According to the Department of Statistics Malaysia, the average of population in Kuala Lumpur has raise $2.4 \%$ in 2015 and now there are 1.79 million of people living in Kuala Lumpur [8,9]. With the growing rate of

\footnotetext{
*Corresponding author's e-mail: salinidevi@ucsiuniversity.edu.my
} 
population especially the residents living in the urban areas such as Kuala Lumpur who are adapting the modern lifestyle, the needs and demands of electrical and electronic gadgets are increasing in modern lifestyle [2].

Households in Malaysia has low awareness in 3R practice which is reduce, reuse and recycle said by the Ministry of Federal Territories [10] and their practice of recycling has not reached the expected level [11]. The recycling effort of households is still low. In Malaysia, there is only $5 \%$ of e-waste collected from households and recycled by Material Recovery Facilities [1]. Malaysians have low awareness about the environment and the impact caused by hazardous substance produced by the e-waste [12].

The e-waste recycle in Malaysia is challenging due to there is no any mechanism can do the proper segregation in a proper way [13]. There are several techniques and technology can be used to deal with e-waste to improve the management of e-waste in Malaysia. For example, government of Malaysia can invest and import the technologies from other developed countries and learn how they manage their e-waste effectively. Using the right way in dealing e-waste can help to reduce the serious impact on environment and human as well as to recover the valuable materials in e-waste [14]. This can help in providing a conducive environment for technology sharing and support sustainable environment [15]. This can ensure that the suppliers of the raw materials are also able to assist the companies and also consumers in implementing a systematic and environmentally-friendly e-waste management system.

Challenges and barriers can be in the form of insufficient technologies and facilities, lack of cooperation among stakeholders, lacking of awareness and etc. These challenges will make the implementation of e-waste management ineffective and the recycling among households become harder. Therefore, this study is conducted to determine and analyze various factors that affect the barriers of E-waste management among the household in Cheras, Malaysia.

\section{METHODOLOGY}

This study used quantitative method to study the relationship between barriers for practicing e-waste management, lack of knowledge, lack of awareness, lack of cooperation and lack of facility.

Figure 1 shows the conceptual framework of this study that indicates the connection between the variables mentioned above and the barriers for practicing waste management in Malaysia. Barriers for practicing e-waste management in Malaysia are because of lack of knowledge about the e-waste and ways to recycle e-waste, lack of awareness on the dangerous of e-waste may bring impacts to the environment and human being, lack of cooperation from the government and households to practice recycling and there is also lack of facilities to collect, assemble and recycle the e-waste.

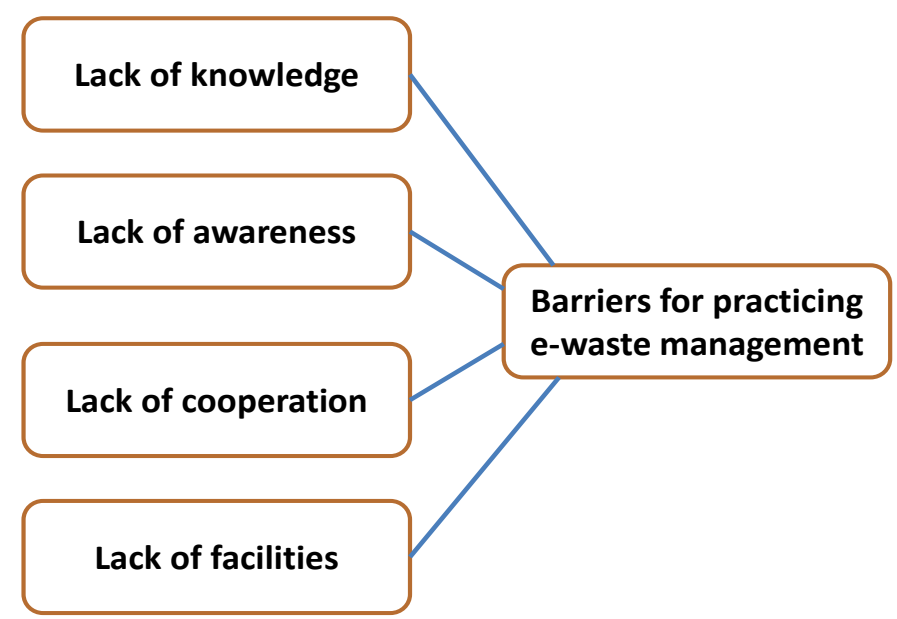

Figure 1. The conceptual framework of Barriers for practicing e-waste management $[16,17]$

\subsection{Data collection}

This study used a survey method to gather the primary data. Structured questionnaires were chosen because it can gather enormous amount of data from a representative sample of respondents. Using this procedure would suitable the research problem. On every incident the primary data are gathered, the new data will be update to current store of social knowledge [18]. In addition, the secondary data involved in this study are the articles, magazine and literature that written by other researchers.

\section{2 arget Population and Location}

The target population of this study will be focus on the household who living in Cheras, Kuala Lumpur and who are the users of electronic and electrical equipment (EEE). The respondents should be users of EEE in order for them to understand the questions that asked in the structured questionnaires.

\subsection{Sampling Technique}

Non-probability, convenience sampling method is used in this study due to fast, inexpensive and the subject always readily available. Moreover, Cheras, Kuala Lumpur has the infinity population and the exact amount of population and number of households who live in Cheras, Kuala Lumpur is hard to determine. 


\subsection{Sampling Size}

The survey based on this study was conducted among respondents who living in Cheras area and the samples that been chose has to be the users of electronic and electrical equipment. The respondents comprise of both gender of people, students or working professionals from different institutions and organizations as well as soleproprietorship. The estimation of the sample size for this research is around 150 respondents.

\subsection{Research Questionnaires}

The data collection method that use in this research is self-administered questionnaires [19-22]. There are 4 sections which included Section A, Section B, Section C and Section D in the self-administered questionnaires. Each of every sections are required the respondents to answer all the questions that related to their socialdemographic profile and the independent variable and dependent variable of the research. These questionnaires contain of 69 questions. Respondents are required to answer the questions based on Yes or No, Nominal Scale and also Likert scale which contained 5 points with the ranging from $1=$ "Totally Disagree" to $5=$ "Totally Agree".

Section A must be related to respondent's demographic variables which contains of 9 items such as gender, age, educational level, income, marital status, employment status and others. This demographic variable is measured by nominal scales. Section B has 10 items to measure the recycling habit of the respondents. Then, section $\mathrm{C}$ with 4 items that measured the respondents' current practices on E-waste Management system. Lastly, section D with 46 statements that measured each independent variable that affect the implementation of e-waste management practices among household in Cheras. The variables are included lack of knowledge, lack of awareness, lack of facility and lack of cooperation. The independent variables are measured by Likert scale.

\subsection{Hypotheses of the Study}

Several hypotheses have been formulated with the intention to provide answers to our research objectives. Relevant findings regarding the relationship between barriers for practicing waste management and the various independent variables mentioned will be uncovered and developed from hypotheses which act as the foundation of research.

\subsubsection{Hypothesis 1}

H0: There is a significant relationship between lack of knowledge and the barriers for practicing waste management in Malaysia.

H1: There is no significant relationship between lack of knowledge and the barriers for practicing waste management in Malaysia.

\subsubsection{Hypothesis 2}

H0: There is a significant relationship between lack of awareness and the barriers for practicing waste management in Malaysia.

H1: There is no significant relationship between lack of awareness and the barriers for practicing waste management in Malaysia.

\subsubsection{Hypothesis 3}

H0: There is a significant relationship between lack of cooperation and the barriers for practicing waste management in Malaysia.

$\mathrm{H} 0$ : There is no significant relationship between lack of cooperation and the barriers for practicing waste management in Malaysia.

\subsubsection{Hypothesis 4}

H0: There is a significant relationship between lack of facility and the barriers for practicing waste management in Malaysia.

H0: There is no significant relationship between lack of facility and the barriers for practicing waste management in Malaysia.

\subsection{Pilot Study}

Pilot test is small-scale of test that conducted by the researchers before the actual research is carried out [23]. The actual research is depending on pilot test in order to test the feasibility and suitability. The response rate of the subjects in the pilot test cannot be used as the response rate of the actual research as the subjects that been used in the pilot test is less statistical basis. The estimation of the sample size for the pilot test will be around 20 respondents.

\subsection{Data Analysis}

\subsubsection{Normality test}

The purpose of performing normality test is ensuring the data is same with the normal [24]. Therefore, if the probability is larger than 0.05 during the normality test, it will be understood that the data are normal. If the probability is smaller than 0.05 , the data will be considered as not normal.

\subsubsection{Reliability test}

Reliability in research can be defined as the capability of the getting the same results after the measurements are repeated on the same subject [23, 25-27]. In a quantitative research, validity will be referring as the capability of all the research instruments to have consistency on measuring the concept in the operational and conceptual phase. Researchers named this capability as internal consistency reliability [23]. Researchers can 
get this internal consistency reliability by comparing the correlation value between the items. Usually, the items that have high internal consistency reliability will have high correlation with the others.

\subsubsection{Multiple Regression Analysis}

Multiple regression analysis is one type of analysis used by researchers to predict the value of one variable based on other variables' values in the research [28]. Researcher named the variable that they want to predict as dependent variable, and those variables that affected the value of the dependent variable as independent variables. In this study, multiple regression analysis can be applied to predict and understand the value of the dependent variable based on the independent variable that has been studies in the literature review.

\section{RESULT AND DISCUSSION}

This study used SPSS 22 student version to analyze the data collected by distributing questionnaire to Cheras household. There are 140 sets of the questionnaires were distributed to the respondents in Cheras household for conducting this study.

\subsection{Normality test}

The normality test is used to measure the score of the scales by using the independent variables which included lack of awareness, lack of knowledge, lack of corporation, lack of facilities and barriers in implementing electronic waste management. These variables are measured by Likert Scale from strongly disagree, disagree, neutral, agree and strongly agree.

\subsubsection{Normality test of lack of awareness}

This section consists of 9 statements in order to measure the independent variable accurately. After analyzed, all the data is on the average. The mode of the total 9 statements is 4.00 , median score is 3.8889 and mean is 3.8135. The histogram in Figure 2 shows that the curve is lying on the majority score around the center of the distribution. The frequency of the respondents is rating with the same score. The majority of the respondents rated agree for the statement, so that the curve lying to the right on 4.00 .

Based on the studies of Sew Tiep et al. [29] stated that Malaysia government is facing the challenges in recycling electronic waste management due to the level of households' awareness is still low and do not know about the environment problem [29]. Moreover, the public is not well informed of the programme which has been carried out by the government [29]. The result of the findings is matched with the studies which show that the respondents are less aware about the electronic waste is increasing rapidly and most of them do not aware about Malaysian government has promoted e-waste recycling in Malaysia.

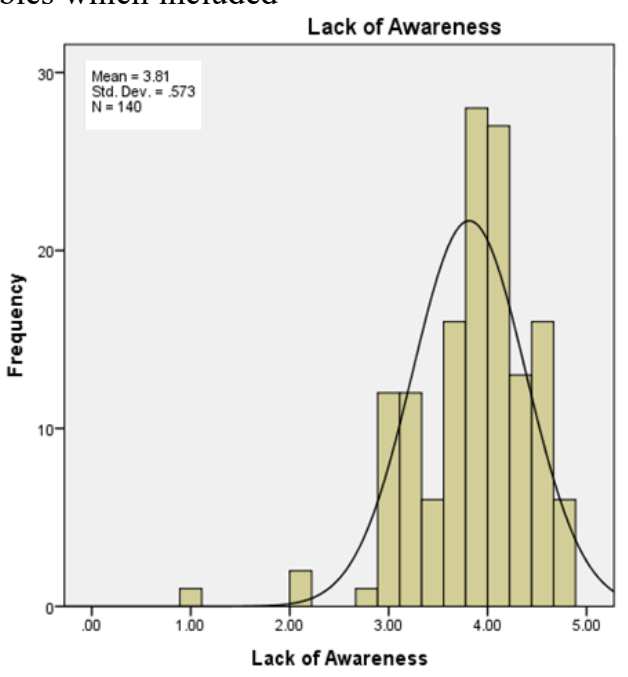

Figure 2. Lack of Awareness

Malaysia government facing this issue is due to the major facts of attitude of Malaysian towards recycling activities [30]. Malaysian government should enforce the regulations directly deal with the e-waste from households and to improve the awareness of the public by held campaigns regularly to promote the important of recycling of e-waste and also to rise the rate of recycles [31].

\subsubsection{Normality test of Lack of knowledge}

This section consists of 8 questions to measure the knowledge of the respondents towards electronic waste management. The histogram in Figure 3 shows the bellshaped curve lying on majority score of 3.50, it shows that the data are very frequent. The frequencies of the respondents are rating to the same score. After analyzed, all the data is on the average. The mode of the total 8 statements is 3.00 , median score is 3.5000 and mean is 3.5330. The majority of the respondents rated agree for the statement, so that the curve lying to the right. 


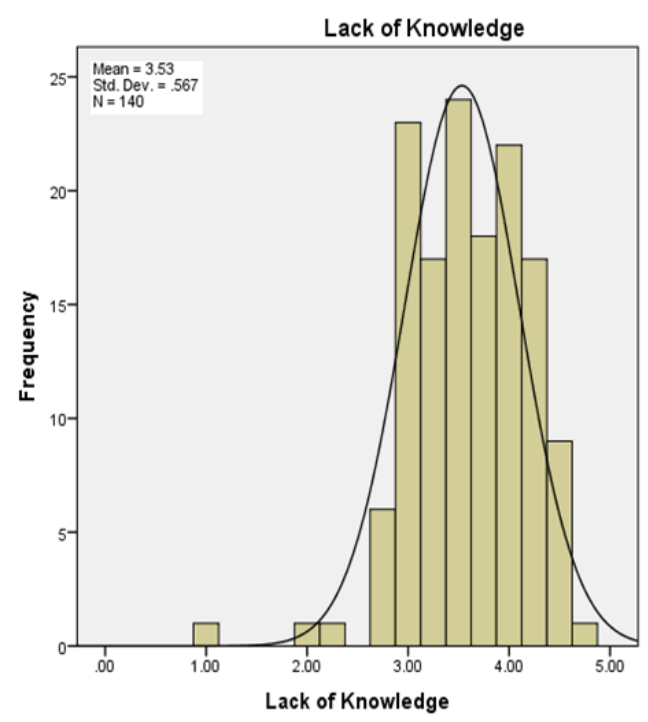

Figure 3. Lack of knowledge

This study finding shows the majority of the respondents feel that the e-waste still have values, therefore they keep it in their house. This can explain the reason of them to keep the e-waste and do not direct throw or recycle it [13]. Based on the study of Ahmand Kalana, 2010., stated that most of the households do not know the proper way in disposing e-waste and how to dispose the electronic waste [31].

Most of the electronic wastes are believed to be end up in landfill sites due to there is without a proper treatment of electronic waste and lack of disposal system to convince Malaysian to recycle e-waste [29]. With proper education and knowledge can guide households in a proper way to discard and recycle their electronic waste [7]. The majorities of the respondents are agreed that people that are highly educated should support and involved themselves in practicing e-waste recycling.

\subsubsection{Normality test in lack of cooperation}

This section consists of 8 questions to measure the cooperation among the respondents and government in order to have effective electronic waste management. The histogram in Figure 4 shows that the data are very frequent. The majority of the respondents are rating at the same scores. After analyzed, all the data is on the average. The mode of the total 8 statements is 3.75 , median score is 3.6250 and mean is 3.5866 . The curve is lying to the right on the center of the bell-shaped.

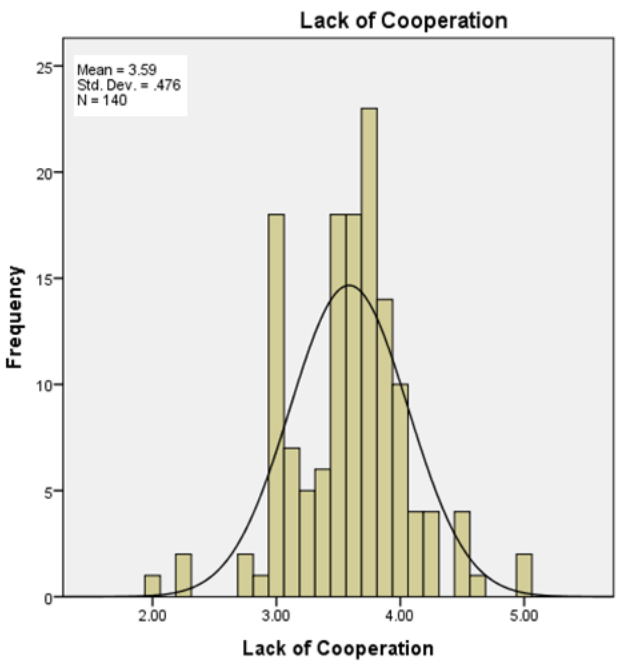

Figure 4. Lack of cooperation

Most of the respondents agreed that they are one of the electronic equipment users so that they are willing to involve themselves in e-waste recycling. The study of Ahmand Kalana shows that Malaysia already enforced regulations on e-waste; however, those regulations do not manage the e-waste from households directly, only practiced in industrial sectors [31]. Therefore, it is still an issue in households. The findings show that the respondents will recycle their e-waste if government enforces the guidelines in electronic waste. The absent of the regulations are the main issue that hindered the effective e-waste management and there is no e-waste regulations implemented in Malaysia currently [1]. According to the study done by Jasmine Adela Mutang et al (2015), residents were not practice recycle due to there is lack of enforcement and they suggest that 'reward and punishment' can encourage residents involved themselves in recycling [16].

Commitment of public is important to increase the rate of e-waste recycling [16]. Recycle efforts are low 
due to the absent of the regulations. Based on the findings, most of the households are willing to involved themselves in sorting e-waste in separated container which is a part of recycling activities. This can help in reducing the works in sorting types of wastes and is one of the positive ways in increasing the rate of e-waste management. The majority of the households are preferred to get back some money rather than paying the recycling fees to the licensed collectors to help them to discard e-waste in a proper way.
This section consists of 10 questions to measure the facilities provided by government and the cooperation among the respondents in order to have effective electronic waste management. The histogram in Figure 5 shows the bell-shaped curve is lying on to the right of the majority score of 4.00 , it shows that the data are very frequent. The frequencies of the respondents are rating to the same score. After analyzed, all the data is on the average. The mode of the total 10 statements is 4.00 , median score is 4.000 and mean is 3.9221 . The majority of the respondents rated agree for the statement.

\subsubsection{Normality test in lack of facilities}

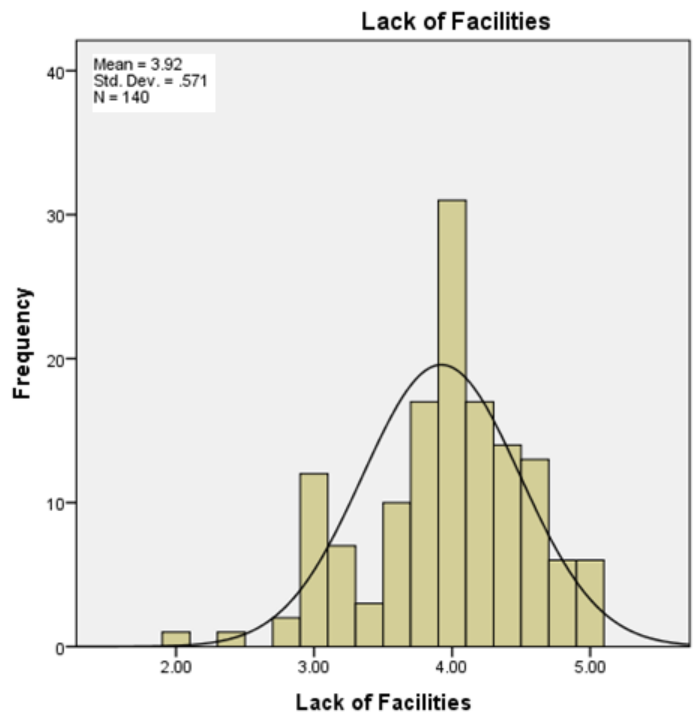

Figure 5. Lack of facilities

Most of the respondents agreed to the statement of 'There is no efficient take back scheme to discard ewaste' which also have been proven by the studied done by Ahmand Kalana [31]. The majority of the respondents in our findings stated that they will participate e-waste recycling if the facilities provided by government in order to have effective e-waste recycling. There is lack of mechanism on a proper segregation and disposal system which should be provided by government to promote to households and encourage them to recycle their e-waste. The households are prefer to get some pay in order to trade the e-waste, rather than for them to pay to the other parties to do. Government should provide take back scheme and a structured mechanism is required to increase the rate of recycling of e-waste [31]. Besides, most of the households are willing to dispose their ewaste if government provide free of charge service to collect e-waste from them. If government can incorporate with the refund schemes can motivate the households practice in recycle of e-waste. Government should also hire more licensed collectors to dispose e-waste in a proper way in order to sustain the environment [12].

\subsubsection{Normality test in barriers of implementing e- waste management}

The histogram in Figure 6 shows the result of normality test in barriers of implementing e-waste management. The households found that it is hard to recycle e-waste due to there is lack of facilities provided. The barriers to have an effective e-waste management causing the ewaste recycle still infant stage. The barriers are included the awareness, knowledge, cooperation of households and facilities provided.

It is important to increase the awareness and knowledge of households in managing the e-waste. The household willingness to participate themselves is also important to help in increasing the rate of recycling ewaste. Households' awareness and knowledge is important in guiding them to recycle. Attitudes, knowledge, enforcement, cooperation, and facilities are the main barriers to improve the participation of household in recycling. Government should enforce laws to guide and motivate households to participate themselves in recycling activities and to be a part of their lifestyle. 


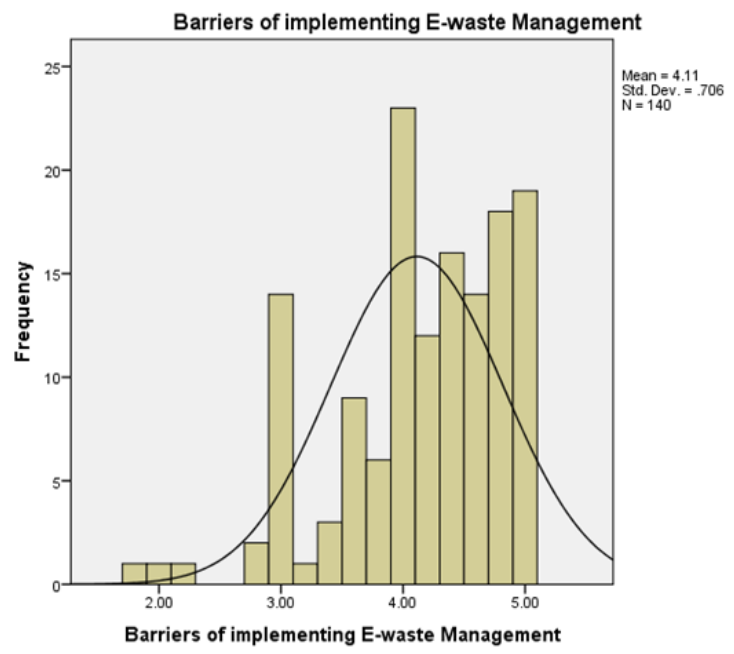

Figure 6. Barriers of implementing e-waste management

\subsection{Reliability Test}

Cronbach's Alpha is chose to use in examining the reliability of this research included the independent variables and dependent variables. The independent variables are included lack of awareness, lack of knowledge, lack of cooperation, and lack of facilities and the dependent variable is the barriers of implementing ewaste management among households. Table 1 shows the Cronbach's Alpha values of 0.908 means that it has high reliable due to the rules stated that if the values are more than 0.6 which indicated that the reliability of the findings is high.

Table 1. Reliability Test

\begin{tabular}{llll}
\hline No. & Independent Variables & Cronbach's Alpha & No. of Items \\
\hline 1 & Reliability Test of Independent Variables & 0.908 & 35 \\
\hline
\end{tabular}

Table 2 shows the dependent variable of the research which refers to the barriers of implementing e-waste recycling has 0.943 of the values of Cronbach's Alpha. The value of the test is more than 0.8 which indicated that the variable is highly reliable. Thus, implement of ewaste management in Malaysia still an issue due to the barriers.

Table 2. Reliability Statistics (Dependent Variable)

\begin{tabular}{cccc}
\hline No. & Dependent Variables & Cronbach's Alpha & No. of Items \\
\hline 1 & Barriers to implement e-waste recycling & 0.943 & 10 \\
\hline
\end{tabular}

Table 3 shows the results of reliability values of all the independent variables are more than 0.6 which refers the scales of measurement are reliable and consistent. The values of independent variables are between the range of 0.651 and 0.872 .

Table 3. Reliability Statistics (Independent Variable)

\begin{tabular}{cccc}
\hline No. & Independent Variables & Cronbach's Alpha & No. of Items \\
\hline 1 & Lack of awareness & 0.872 & 9 \\
2 & Lack of knowledge & 0.740 & 8 \\
3 & Lack of cooperation & 0.651 & 8 \\
4 & Lack of facilities & 0.865 & 10 \\
\hline
\end{tabular}

\subsection{Multiple Regression Analysis}

Regression test is used to test the data and predict the values of dependent variable and independent variables. There are 4 independent variables in the research which are included lack of awareness, lack of knowledge, lack of cooperation and lack of facilities. The $\mathrm{R}$ value is 0.791 , values of $\mathrm{R}$ Square is 0.626. Meanwhile, adjusted $\mathrm{R}$ Square is 0.615 .

\subsubsection{Test of significant}

Table 4 shows that the significant value for lack of awareness is 0.027 . This value is less than 0.05 . Thus H1 is accepted, which means that lack of awareness has significant relationship to the barriers of implementing ewaste management. Table 4 shows that the significant value for lack of knowledge is 0.001 . This value is less than 0.05 . Thus H1 is accepted, which means that lack of knowledge has significant relationship to the barriers of implementing e-waste management. Table 4 shows that the significant value for lack of cooperation is 0.001 . This value is less than 0.05 . Thus $\mathrm{H} 1$ is accepted, which means that lack of cooperation has significant relationship to the barriers of implementing e-waste management. Table 4 shows that the significant value for lack of facilities is 0.000 . This value is less than 0.05 . 
Thus H1 is accepted, which means that lack of facilities has significant relationship to the barriers of

Table 4. Multiple Regression Analysis (Dependent Variable: barrier of implementing e-waste management)

\begin{tabular}{ccccccc}
\hline & \multicolumn{2}{c}{$\begin{array}{c}\text { Unstandardized } \\
\text { Coefficients }\end{array}$} & $\begin{array}{c}\text { Standardized } \\
\text { Coefficients }\end{array}$ & Beta & & Sig. \\
\cline { 2 - 5 } & $\mathbf{B}$ & Std. Error & & -1.991 & .048 \\
(Constant) & -.661 & .332 & .154 & 2.238 & .027 \\
awareness & .190 & .085 & .191 & 3.276 & .001 \\
knowledge & .238 & .073 & .249 & 3.421 & .001 \\
cooperation & .370 & .108 & .388 & 5.005 & .000 \\
facilities & .480 & .096 & & & \\
\hline
\end{tabular}

Based on Table 4, the independent variable is lack of facilities which is the main reason that causes the barriers of implementing e-waste management. It has the regression coefficient of 0.480 . This refers that one unit increase in facilities will decrease the barriers of implementing e-waste management by 0.480 units. Besides, it followed by lack of cooperation (0.370), lack of knowledge (0.238) and lack of awareness (0.190) which are the reasons affecting the barriers of implementing e-waste management.

Moreover, the Beta values (standardized coefficients) analyzed which the independent variables are the most and least influential to the barriers of implementing ewaste management by using those four independent variables. Based on Table 4, shows that lack of facilities has the highest Beta value of 0.388 which is the most influential independent variables towards the barriers of implementing e-waste management. However, the lowest
Beta value of 0.154 is lack of awareness which has the weak influential towards the barriers of implementing ewaste management.

\subsubsection{Analysis of ANOVA}

The table 4.17 shows the ANOVA has significant with $\mathrm{F}$ ration $=56.459$ and the $\mathrm{P}$ values is 0.000 . Therefore, the equation is created as the barriers of implementing ewaste management is the sum of the lack of awareness, lack of knowledge, lack of cooperation and lack of facilities. Barriers of implementing e-waste management $=-0.661+0.190$ (lack of awareness) +0.238 (lack of knowledge) +0.370 (lack of cooperation) +0.480 (lack of facilities). Thus, there is a positive relationship of lack of awareness, lack of knowledge, lack of cooperation and lack of facilities.

Table 5. ANOVA of lack of awareness, lack of knowledge, lack of cooperation, lack of facilities and barriers of implementing e-waste management

\begin{tabular}{cccccc}
\hline Model & Sum of Squares & df & Mean Square & F & Sig. \\
\hline Regression & 43.333 & 4 & 10.833 & 56.459 & $.000^{\mathrm{a}}$ \\
Residual & 25.904 & 135 & .192 & \\
Total & 69.237 & 139 & & & \\
\hline a. Predictors: (Constant), facilities, knowledge, awareness, cooperation & & \\
\hline
\end{tabular}

\section{Conclusion}

This study has identified 4 independent variables that will affect the implementation of e-waste management among household in Cheras which is lack of awareness, lack of knowledge, lack of cooperation and lack of facilities. Among these four variables, lack of facilities has the strongest relationship with the barriers of implementing e-waste management among household in Cheras as it has the lowest significant value which was 0.000 . All of the hypotheses reveal the 4 barriers which was lack of awareness, lack of knowledge, lack of cooperation, lack of facilities are significant. These mean that all of independent variables have a positive relationship with the barriers of implementing e-waste management among households in Cheras. Besides the rules and regulations, government has to organize educational seminars or talks regarding to the e-waste to boost the households' awareness level and knowledge. Government also can implement the teaching of e-waste management to increase the knowledge to the young generations because most of the EEE consumers are from the youngster.

\section{References}

1. Tiep, H., Kin, T., Ahmed, E. and Teck, L. (2015). E-Waste Management Practices of Households in Melaka. IJESD, 6(11), pp.811-817.

2. Akhtar, R., Mahedi Masud, M. and Afroz, R. (2014). Household perception and recycling behaviour on electronic waste management: A case study of Kuala Lumpur, Malaysia. Malaysian Journal of Science, pp.32-41.

3. Bodamer, David. "The 20 Countries That Generated the Most E-Waste Last Year". Waste360. N.p., 2015. Web. 25 Sept. 2016.

4. Wang, Z., Zhang, B., Yin, J. and Zhang, X. (2011). Willingness and behavior towards e-waste recycling for residents in Beijing city, China. Journal of Cleaner Production, 19(9-10), pp.977-984. 
5. Song, Q., Wang, Z. and Li, J. (2012). Residents' behaviors, attitudes, and willingness to pay for recycling e-waste in Macau. Journal of Environmental Management, 106, pp.8-16.

6. Thestar.com.my. (2014). Growing e-waste problem - Environment | The Star Online. [online]

7. Faizah Haron, N. (2015). Determinants of E-Waste Recycling In Putrajaya, Malaysia: An Application Of Amos Graphic. The International Journal of Social Sciences, 39(1).

8. Statistics.gov.my. (2016). Department of Statistics Malaysia Official Portal. [online] Available at: https://www.dosm.gov.my/v1/

9. Rajendran, S.D., and Wahab, S.N. (2017) Purchasing Intention towards Green Packaged Products: An Exploratory Study among Malaysian Consumers, 3rd International Conference on Advanced Research in Business and Social Sciences, 29-30 March, 347-355.

10. Mysinchew.com. (2016). Recycling awareness still low. [online] Available at: http://www.mysinchew.com/node/82189 [Accessed 22 Sep. 2016].

11. Zamani, Z. (2016). Malaysia's recycling rate is still low. [online] Available at: http://www.thesundaily.my/news/1391122 [Accessed 22 Sep. 2016].

12. Afroz, R., Masud, M., Akhtar, R. and Duasa, J. (2013). Survey and analysis of public knowledge, awareness and willingness to pay in Kuala Lumpur, Malaysia - a case study on household WEEE management. Journal of Cleaner Production, 52, pp.185-193.

13. Jaibee, S., Abd Rahim, A., Mohamad, F., Jamian, S., Kiong, S., Seiji, Y. and Muhd Nor, N. (2015). Review on Current Status of Waste Electric and Electronic Product in Malaysia. AMM, 773-774, pp.898-907.

14. Chibunna, J., Siwar, C., Begum, R. and Mohamed, A. (2012). The Challenges of E-waste Management Among Institutions: A Case Study of UKM. Procedia - Social and Behavioral Sciences, 59, pp.644-649.

15. Desa, A., Kadir, N. and Yusooff, F. (2012). Waste Education and Awareness Strategy: Towards Solid Waste Management (SWM) Program at UKM. Procedia - Social and Behavioral Sciences, 59, pp.47-50.

16. Adela Mutang, J., Ismail, R., Bee Seok, C., Bahari, F., Madlan, L., Wider, W. and Das, R. (2015). Recycling Motivations and Barriers in Kota Kinabalu, Malaysia. International Journal of Social, Behavioral, Educational, Economic, Business and Industrial Engineering, 9(8).

17. Jia Sin, Tey et al.2013 "Current Practice of Waste Management System in Malaysia: Towards Sustainable Waste Management".

18. Hox, J. and Boeije, H. (2005). Data Collection, Primary vs Secondary. The Encyclopedia of Social Measurement, 1.

19. Wahab, S.N., \& Khong W.L. (2018). Multiple
Linear Regression Modelling of Parcels' Distribution Design Factors and online Shopping Customer Satisfaction. International Journal of Modelling in Operations Management, 7(2), 95-110.

20. Wahab, S.N., Rajendran, S.D., Yeah N.K., \& Deng Y. (2017). Antecedents Influencing E-Service Quality towards Customer Loyalty among Malaysian Online Shoppers. 3rd International Conference on Advanced Research in Business and Social Sciences, 29-30 March, 337-346, Langkawi Malaysia.

21. Teo, A.C., Tan, G.W.H., Ooi, K.B, Hew, T.S and Yew, K.T. (2015) 'The Effects of Convenience and Speed in M-Payment Usage', Industrial Management and Data Systems, Vol. 115 No. 2, 311-331

22. Ling E.K. \& Wahab, S.N. (2018). Integrity of Food Supply Chain: Going beyond Food Safety and Food Quality. International Journal of Productivity and Quality Management, DOI: 10.1504/IJPQM.2019.10019297.

23. Chua, Y. (2012). Mastering research methods. 1st ed. Kuala Lumpur: McGraw-Hill Education.

24. Anon, (2016). The Effects of Socio-Economic Influences on Households [online] Available at:The Rakyat Post. N.p., 2015. Web. 12 Oct. 2016.

25. Chong, J. L., Chong, A. Y. L., Ooi, K. B., \& Lin, B. (2011). An empirical analysis of the adoption of $\mathrm{m}$ learning in Malaysia. International Journal of Mobile Communications, Vol. 9 No.1, 1-18.

26. Rajendran, S.D., Wahab, S.N, Ling, Y.W., and Yun, L.S. (2018). The Impact of Logistics Services On the E-Shoppers' Satisfaction, International Journal of Supply Chain Management, 7(5), pp. 461-469.

27. Wahab, S.N., Bahar, N. \& Mat Radzi, N.A. (2019). An Inquiry on Knowledge Management in Thirdparty Logistics Companies. International Journal of Business Innovation and Research, DOI: 10.1504/IJBIR.2020.10024101.

28. Statistics.laerd.com. (2016). How to perform a Multiple Regression Analysis in SPSS Statistics | Laerd Statistics. [online] Available at: https://statistics.laerd.com/spss-tutorials/multipleregression-using-spss-statistics.php [Accessed 23 Nov. 2016]

29. Sew Tiep, H., Yoon Kin, D., Ahmed, E., \& Chee Teck, L. (2015). E-Waste Management Practices of Households in Melaka. International Journal of Environment Science and Development, 6(11). http://dx.doi.org/10.7763/IJESD.2015.V6.704

30. Akhtar, R., Mehedi Masud, M. and Afroz, R. (2014) Household Perception And Recycling Akil, A., Foziah, J. and Ho, C. (2015).

31. Ahmand Kalana, J. (2010). Electrical and Electronic Waste Management Practices by households in Shah Alam, Selangor, Malaysia. International Journal of Environmental Sciences, 1(2). 